\title{
Evaluation of the Princeton Ocean Model Using South China Sea Monsoon Experiment (SCSMEX) Data
}

\author{
Peter C. Chu \\ Department of Oceanography, Naval Postgraduate School, Monterey, California \\ ShiHua Lu AND Yuchun CHEN \\ Cold and Arid Regions Environmental and Engineering Research Institute, Lanzhou, China
}

(Manuscript received 30 May 2000, in final form 15 February 2001)

\begin{abstract}
The Princeton Ocean Model (POM) has been implemented in the South China Sea for hindcast of circulation and thermohaline structure. A two-step technique is used to initialize POM with temperature, salinity, and velocity for 1 April 1998 and integrate it from 1 April 1998 with synoptic surface forcing for 3 months with and without data assimilation. Hydrographic and current data acquired from the South China Sea Monsoon Experiment (SCSMEX) from April through June 1998 are used to verify, and to assimilate into, POM. The mean SCSMEX data (Apr-Jun 1998) are about $0.5^{\circ} \mathrm{C}$ warmer than the mean climatological data above the $50-\mathrm{m}$ depth, and slightly cooler than the mean climatological data below the 50-m depth, and are fresher than the climatological data at all depths and with the maximum bias $(0.2-0.25 \mathrm{ppt})$ at $75-\mathrm{m}$ depth.

POM without data assimilation has the capability to predict the circulation pattern and the temperature field reasonably well, but has no capability to predict the salinity field. The model errors have Gaussian-type distribution for temperature hindcast, and non-Gaussian distribution for salinity hindcast with six to eight times more frequencies of occurrence on the negative side than on the positive side. Data assimilation enhances the model capability for ocean hindcast, if even only conductivity-temperature-depth (CTD) data are assimilated. When the model is reinitialized using the assimilated data at the end of a month (30 Apr; 31 May 1998) and the model is run for a month without data assimilation (hindcast capability test), the model errors for both temperature and salinity hindcast are greatly reduced, and they have Gaussian-type distributions for both temperature and salinity hindcast. Hence, POM gains capability in salinity hindcast when CTD data are assimilated.
\end{abstract}

\section{Introduction}

The South China Sea (SCS) is a semienclosed tropical sea located between the Asian landmass to the north and west, the Philippine Islands to the east, Borneo to the southeast, and Indonesia to the south (Fig. 1), a total area of $3.5 \times 10^{6} \mathrm{~km}^{2}$. It includes the shallow Gulf of Thailand and connections to the East China Sea (through the Taiwan Strait), the Pacific Ocean (through the Luzon Strait), the Sulu Sea, the Java Sea (through the Gasper and Karimata Straits), and to the Indian Ocean (through the Strait of Malacca). All of these straits are shallow except Luzon Strait whose maximum depth is $1800 \mathrm{~m}$. Consequently, the SCS is considered a semienclosed sea. The complex topography includes a broad shallow shelf in the south-southwest; the continental shelf of the Asian landmass in the north, extending from the Gulf of Tonkin to Taiwan Strait; a deep, elliptical shaped

Corresponding author address: Dr. Peter C. Chu, Department of Oceanography, Naval Postgraduate School, Monterey, CA 93943.

E-mail: chu@nps.navy.mil basin in the center; and numerous reef islands and underwater plateaus scattered throughout. The shelf that extends from the Gulf of Tonkin to the Taiwan Strait is consistently nearly $70 \mathrm{~m}$ deep, and averages $150 \mathrm{~km}$ in width; the central deep basin is $1900 \mathrm{~km}$ along its major axis (northeast-southwest) and approximately $1100 \mathrm{~km}$ along its minor axis, and extends to over $4000 \mathrm{~m}$ deep. The south-southwest SCS shelf is the submerged connection between Southeast Asia, Malaysia, Sumatra, Java, and Borneo and reaches 100-m depth in the middle; the center of the Gulf of Thailand is about $70 \mathrm{~m}$ deep.

The SCS is subjected to a seasonal monsoon system (Wyrtki 1961). From April to August, the weaker southwesterly summer monsoon winds result in a monthly mean wind stress of just over $0.1 \mathrm{~N} \mathrm{~m}^{-2}$ (Fig. 2a). From November to March, the stronger northeasterly winter monsoon winds corresponds to a maximum monthly mean wind stress of nearly $0.3 \mathrm{~N} \mathrm{~m}^{2}$ (Fig. 2b). The transitional periods are marked by highly variable winds and surface currents.

A survey by Wyrtki (1961), which was modeled by 


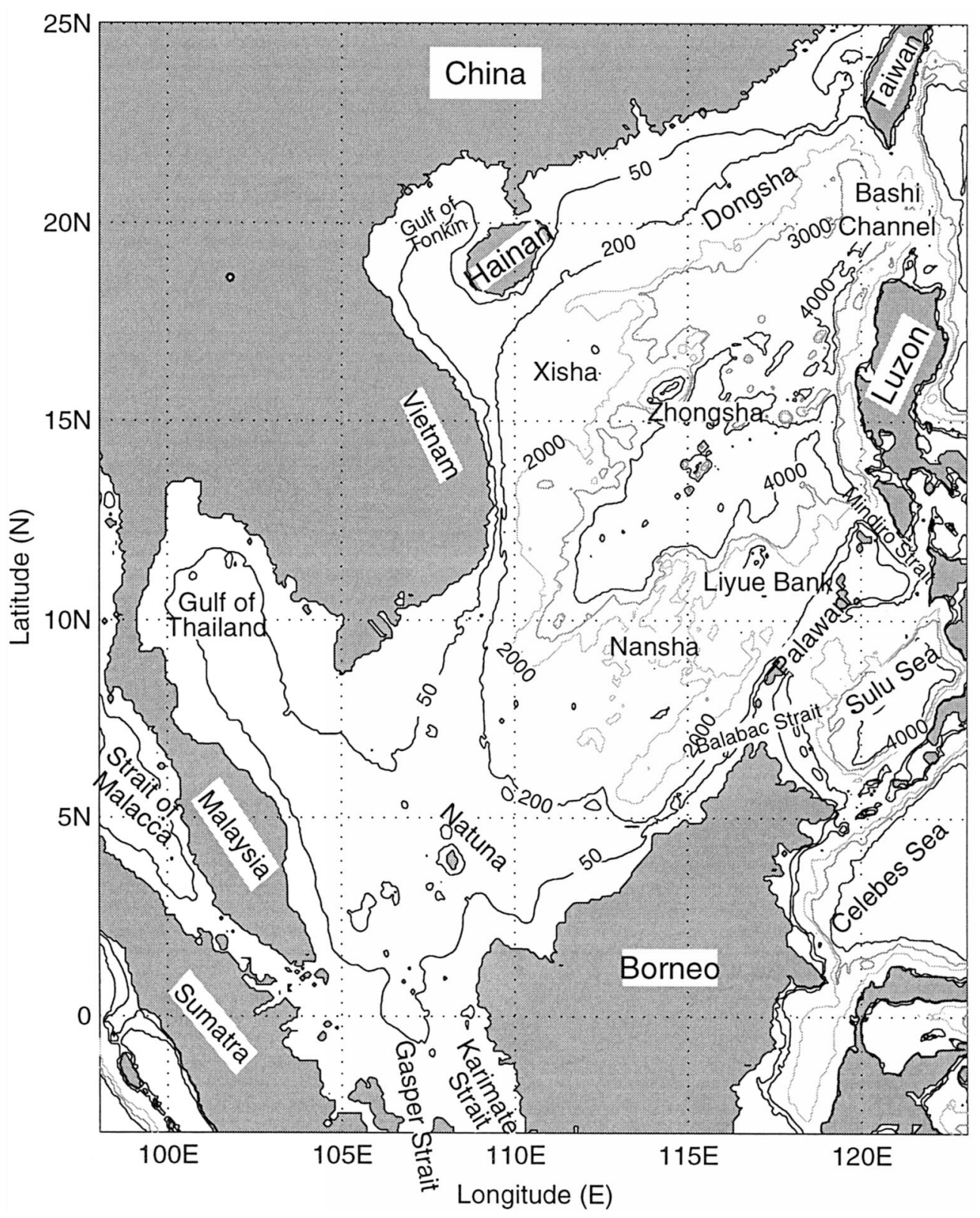

FIG. 1. Geography and isobaths showing the bottom topography of the South China Sea. Numbers show the depth $(\mathrm{m})$.

Chu et al. (1999a), using the Princeton Ocean Model $(\mathrm{POM})$ revealed complex temporal and spatial features of the surface currents in both the SCS and the surrounding waters. The surface circulations for the summer (Jun-Aug) show the strong western boundary current flowing northward to northeastward (Fig. 3a). By April, the northeast monsoon has decayed and the main SCS current consisted of two large areas of anticyclonic flow in the western SCS, one in the north and the other in the south. With the beginning of the southwest monsoon in May and June, a wind drift current is formed. Off the coast of Vietnam, westward intensification of this current is clearly visible. The wide, uniform drift in the northern SCS shows a deflection of the current to the right of the wind (Fig. 3a). The winter circulations indicate a reverse pattern: the western boundary current flowing southward to southeastward. The southern SCS is occupied by a cyclonic flow (Fig. 3b). The simulated SCS surface circulation patterns agree with the observational results quite well (see Plates 3 and 6 in Wyrtki 1961).

The observed circulation patterns of the intermediate to upper layers of the SCS are primarily forced by the local monsoon systems (Wyrtki 1961), with contribu- 
(a)

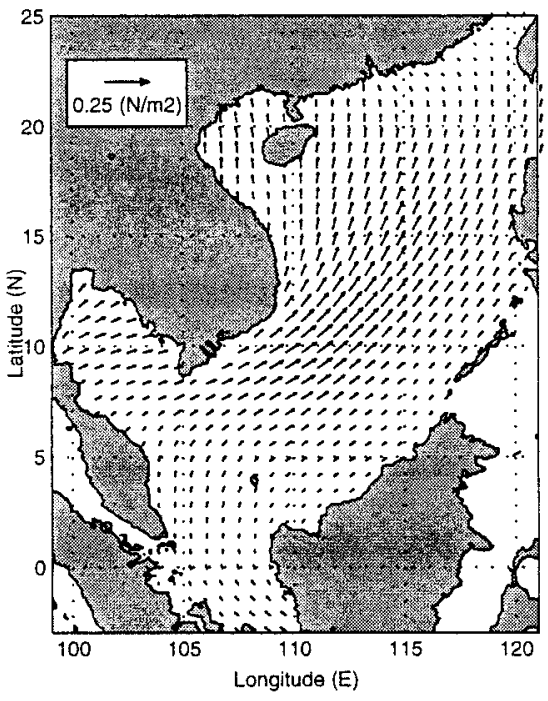

(b)

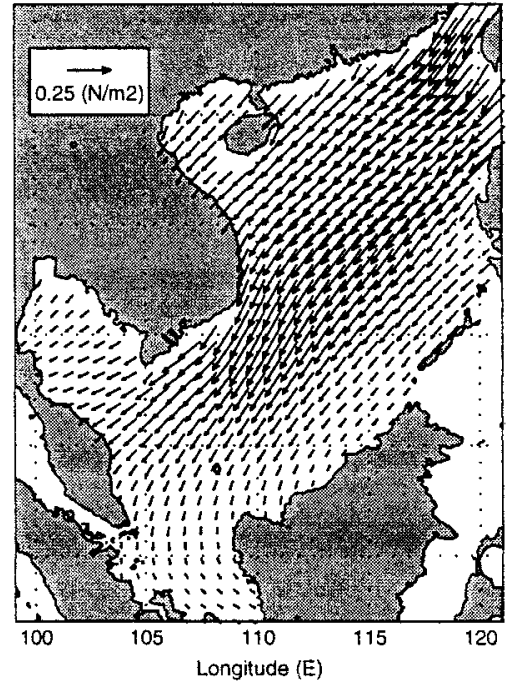

FIG. 2. Climatological wind stress vectors obtained from COADS (da Silva 1994): (a) Jun and (b) Dec.

tions from the Kuroshio Current via the Bashi Channel. The Kuroshio entered the SCS through the southern side of the channel, then executed a tight, anticyclonic turn, and exited the SCS near Taiwan. An estimated 6.5 Sv (1 $\left.\mathrm{Sv}=10^{6} \mathrm{~m}^{3} \mathrm{~s}^{-1}\right)$ of the intrusion passed through Bashi Channel (Chu and Li 2000) using the navy's climatological temperature and salinity dataset (public domain) with $1 / 2^{\circ} \times 1 / 2^{\circ}$ resolution by the P-vector method. This flow exerted a strong influence on the properties of the northern SCS waters and is believed to contribute to currents in the Taiwan Strait (Hu and Liu 1992).
The Naval Oceanographic Office (NAVOCEANO) and the Fleet Numerical Meteorology and Oceanography Center (FNMOC) are the major operational environmental processing centers. Both NAVOCEANO and FNMOC are interested in comparisons of advanced numerical analysis and ocean nowcast/hindcast models leading to model improvements. The South China Sea Monsoon Experiment (SCSMEX) provides a unique opportunity for such an evaluation. Hydrographic and current data acquired from SCSMEX for April through June 1998 are used to verify, and to assimilate into, POM. (a)

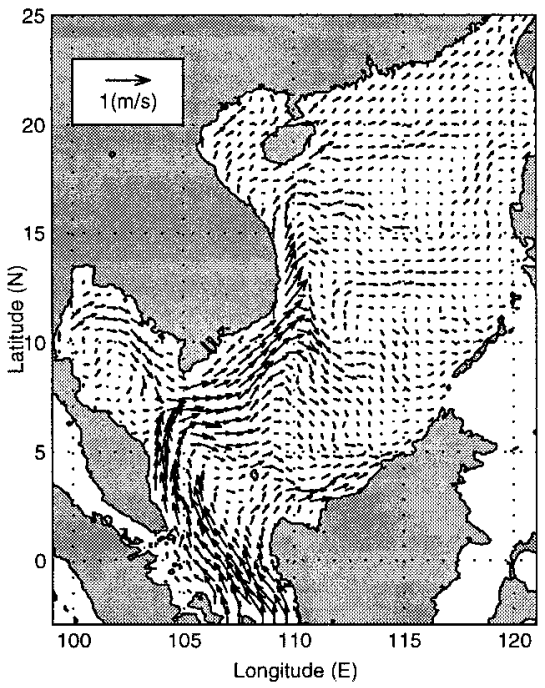

(b)

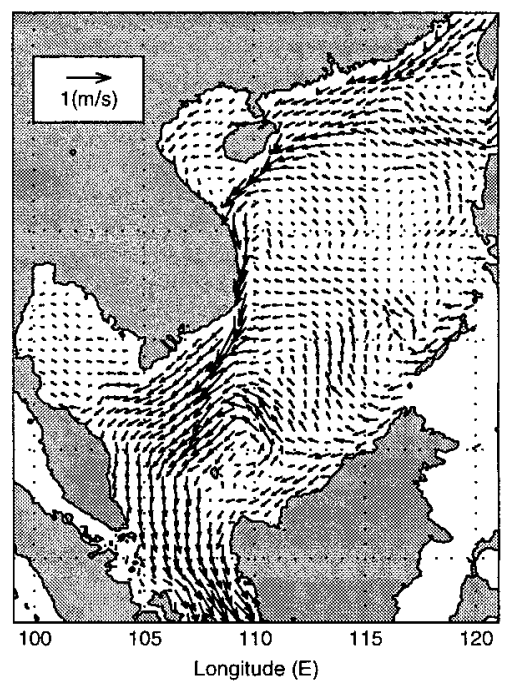

FIG. 3. Mean surface circulation simulated using POM-SCS: (a) summer and (b) winter. [After Chu et al. (1999a).] 

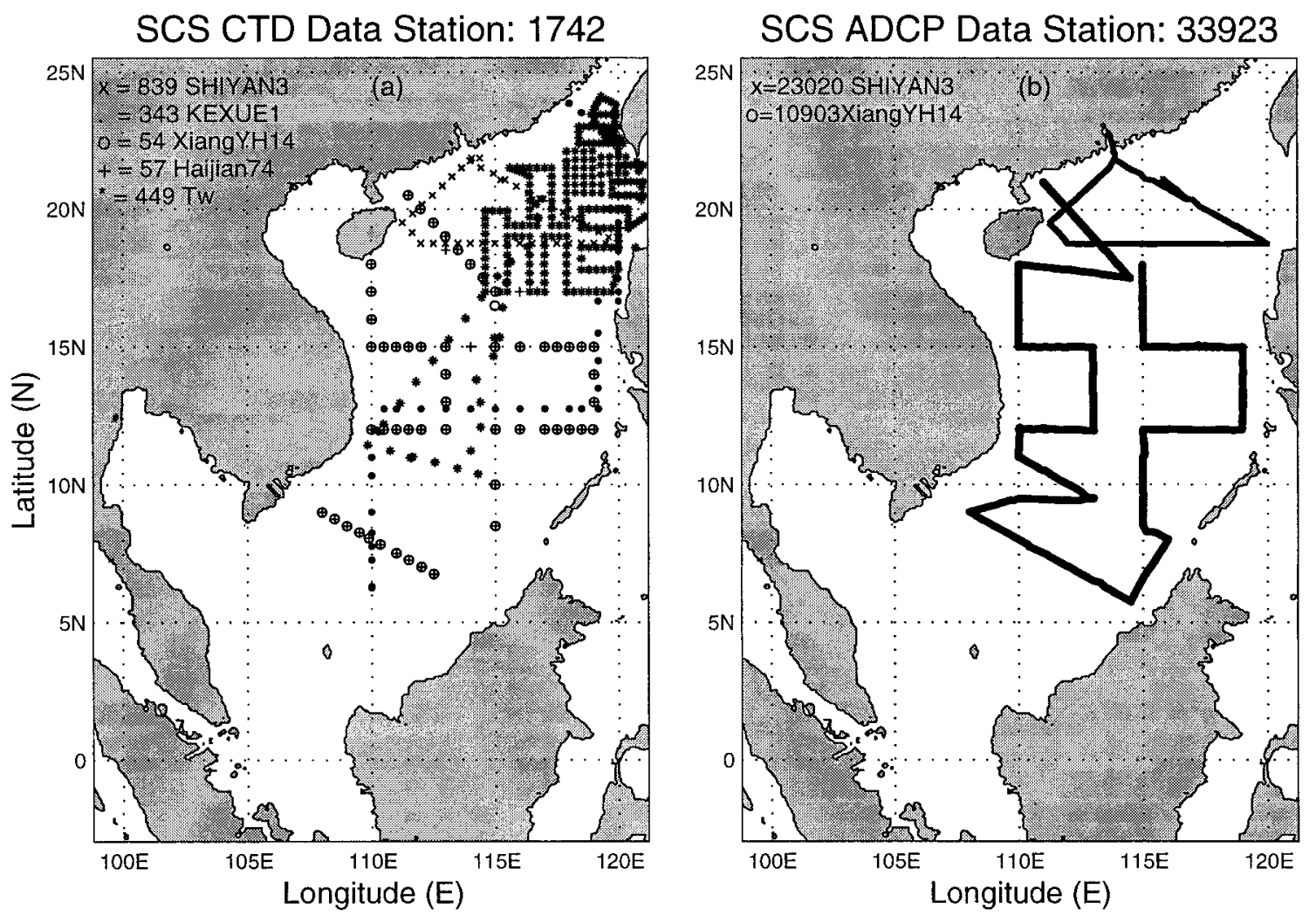

FIG. 4. The SCSMEX oceanographic observations: (a) CTD stations and (b) ADCP stations.

\section{Oceanographic observations during SCSMEX}

\section{a. Description}

SCSMEX is a large-scale experiment to study the water and energy cycles of the Asian monsoon regions with the goal (SCSMEX Science Working Group 1995) to provide a better understanding of the key physical processes responsible for the onset, maintenance, and variability of the monsoon over Southeast Asia and southern China leading to improved predictions. It involves the participation of all major countries and regions of East and Southeast Asia, as well as Australia and the United States.

SCSMEX had both atmospheric and oceanic components. The oceanic intensive observational period (IOP) was from April through June 1998 with shipboard measurements, ATLAS moored array, and drifters. The hydrographic data collected during the SCSMEX IOP went through quality control procedures, such as a minimum-maximum check (e.g., disregarding any temperature data less than $-2^{\circ} \mathrm{C}$ and greater than $40^{\circ} \mathrm{C}$ ), an error anomaly check (e.g., rejecting temperature data deviating more than $7^{\circ} \mathrm{C}$ from climatology), a shiptracking algorithm (screening out data with obvious ship position errors), a maximum number limit (limiting a maximum number of observations within a specified and rarely exceeded space-time window), and a buddy check (tossing out contradicting data). The climatolog- ical data used for quality control are depicted in Chu et al. (1997a,b). After the quality control, the SCSMEX oceanographic dataset contains 1742 CTD stations (Fig. 4a) and 33923 Acoustic Doppler Current Profiler (ADCP) stations (Fig. 4b). The majority of the CTDs were nominally capable of reaching a maximum depth of $2000 \mathrm{~m}$.

\section{b. $T-S$ diagram}

The monthly CTD station distribution during SCSMEX 1998 (Fig. 5) shows good coverage for the SCS basin. The corresponding T-S diagrams (opposite$\mathrm{S}$ shape T-S curves) clearly show the existence of five water masses: the SCS surface water (SCSSW, warm and less fresh), the SCS subsurface water (SCSSSW, less warm and salty), the SCS intermediate water (SCSIW, less cool and fresh), the SCS deep water (SCSDW, cool and fresher), and the SCS coastal water (SCSCW, cool and fresh). The characteristics of the five water masses are illustrated in Table 1.

\section{c. Current field}

The SCSMEX ADCP data at 20-m depth show the existence of multieddy structure in SCS (Fig. 6a) with north cyclonic-south anticyclonic dipoles $\left(9^{\circ}-14^{\circ} \mathrm{N}\right.$, $110^{\circ}-113^{\circ} \mathrm{E}$ ) near the Vietnamese Bight, an anticyclonic 

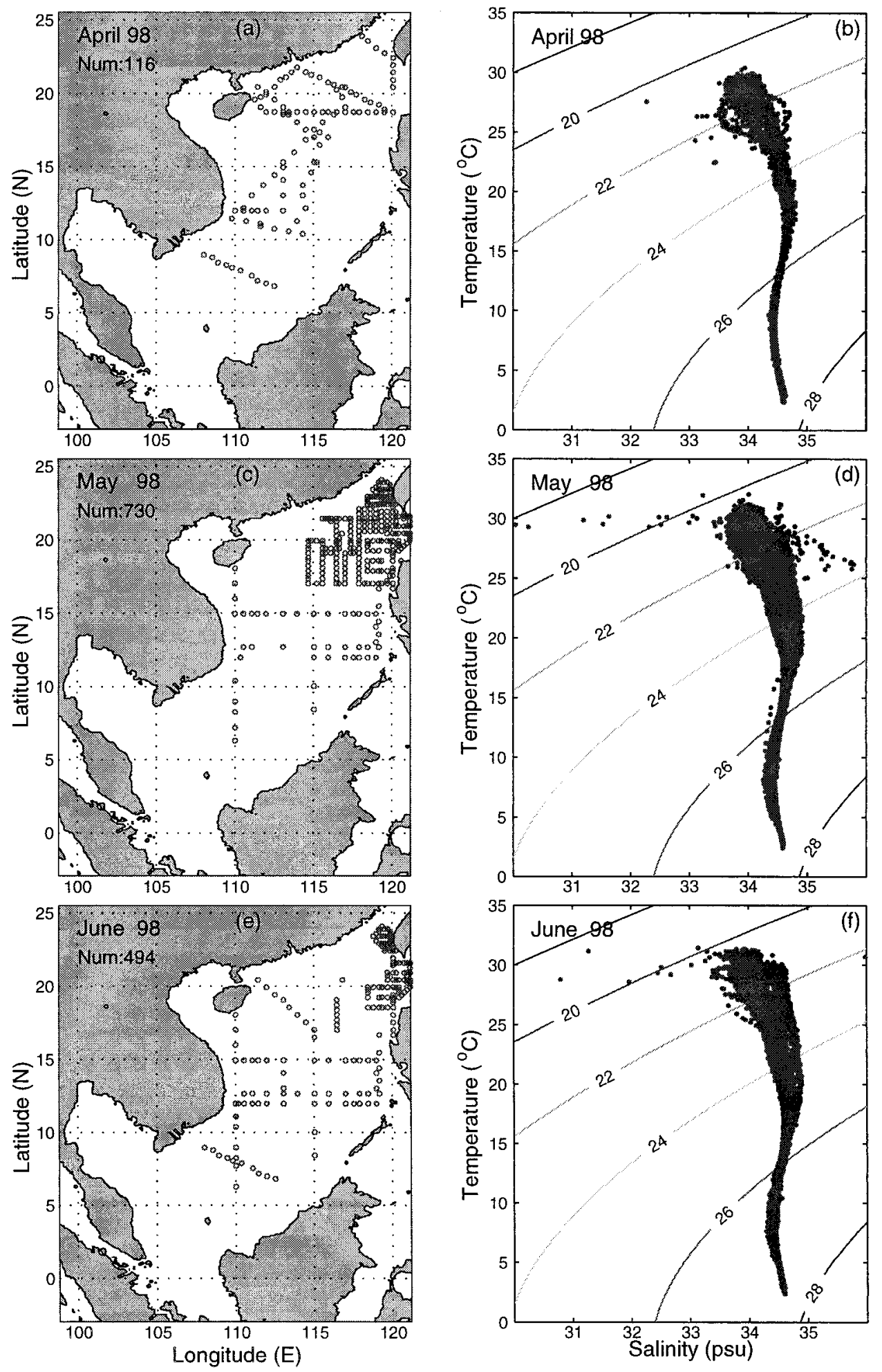

FIG. 5. CTD stations during SCSMEX-1998 and corresponding T-S diagrams. 
TABLE 1. Hydrographic features of the five SCS waters.

\begin{tabular}{lccc}
\hline \hline Water mass & Temperature $\left({ }^{\circ} \mathrm{C}\right)$ & Salinity $(\mathrm{ppt})$ & Depth $(\mathrm{m})$ \\
\hline SCSSW & 27.5 & 33.75 & $<50$ \\
SCSSSW & 20.5 & 34.72 & $50-200$ \\
SCSIW & 7.0 & 34.36 & $200-600$ \\
SCSDW & 2.0 & 34.64 & $>1000$ \\
SCSCW & 17.0 & 33.24 & $<50$ \\
\hline
\end{tabular}

eddy $\left(8^{\circ}-13^{\circ} \mathrm{N}, 115^{\circ}-120^{\circ} \mathrm{E}\right)$ west of Palawan Island, and a cyclonic eddy $\left(17^{\circ}-21^{\circ} \mathrm{N}, 110^{\circ}-113^{\circ} \mathrm{E}\right)$ east of Hainan Island.

\section{Model}

\section{a. Description}

POM is a time-dependent, primitive equation circulation model on a three-dimensional grid that includes realistic topography and a free surface. Developed at Princeton University (Blumberg and Mellor 1987), the model was specifically designed to accommodate mesoscale phenomena, including the often nonlinear processes (such as upwelling and eddy dynamics) commonly found in estuarine and coastal oceanography. Several years ago POM was implemented in the domain $\left(3.06^{\circ} \mathrm{S}-25.07^{\circ} \mathrm{N}, 98.84^{\circ}-121.16^{\circ} \mathrm{E}\right)$ covering the whole SCS and surrounding land and islands (Chu et al. 1998a, 1999a). POM has the capability to simulate the SCS multieddy structure detected from both historical (Chu et al. 1997a,b) and synoptic data (Chu et al. 1998c) and to simulate the SCS response to a tropical cyclone (Chu et al. 2000b). POM is also a useful tool for investigating the mechanisms for the seasonal variability (Chu et al. 1999a) and eddy formation (Chu et al. 1998a). Recently, a coastal atmosphere-ocean coupled system was developed with POM as the oceanic component and the Pennsylvania State University-National Center for Atmospheric Research fifth-generation Mesoscale as the atmospheric component (Chu et al. 1999b).

In this study, the horizontal spacing is $0.179^{\circ}$ by $0.175^{\circ}$ (approximately $20-\mathrm{km}$ resolution) and there are 23 vertical sigma coordinate levels. Consequently, the model contains $125 \times 162 \times 23$ fixed grid points. The model uses realistic bathymetric data from the NAVOCEANO Digital Bathymetry Data Base (NAVOCEANO 1998) $5 \mathrm{~min}$ by $5 \mathrm{~min}$ resolution. The horizontal diffusion coefficient is chosen to be 0.2 for this application. The bottom stress $\tau_{b}$ is assumed to follow a quadratic law (Blumberg and Mellor 1987).

\section{b. Atmospheric forcing}

The atmospheric forcing for the SCS application of POM includes mechanical and thermohaline forcing. The wind forcing is determined by

$$
\rho_{0} K_{M}\left(\frac{\partial u}{\partial z}, \frac{\partial v}{\partial z}\right)_{z=0}=\left(\tau_{0 x}, \tau_{0 y}\right)
$$

TABLE 2. Bimonthly variation of volume transport (Sv) at the lateral open boundaries. The positive (negative) values mean outflow (inflow) and were taken from Wyrtki (1961).

\begin{tabular}{lrrrrrr}
\hline \hline & Feb & Apr & Jun & Aug & Oct & Dec \\
\hline Gaspar and Kari- & & & & & & \\
$\quad$ mata Straits & 4.4 & 0.0 & -4.0 & -3.0 & 1.0 & 4.3 \\
Luzon Strait & -3.5 & 0.0 & 3.0 & 2.5 & -0.6 & -3.4 \\
Taiwan Strait & -0.9 & 0.0 & 1.0 & 0.5 & -0.4 & -0.9 \\
\hline
\end{tabular}

where $K_{M}$ is the vertical mixing coefficient for momentum, and $(u, v)$ and $\left(\tau_{0 x}, \tau_{0 y}\right)$ are the two components of the water velocity and wind stress vectors, respectively.

Surface thermal forcing is determined by

$$
\begin{gathered}
K_{H} \frac{\partial \theta}{\partial z}=\alpha_{1}\left(\frac{Q_{H}}{\rho C_{p}}\right)+\alpha_{2} C\left(\theta_{\mathrm{OBS}}-\theta\right) \\
K_{S} \frac{\partial S}{\partial z}=\alpha_{1} Q_{S}+\alpha_{2} C\left(S_{\mathrm{OBS}}-S\right), \\
Q_{S}=S\left(E-P_{r}\right),
\end{gathered}
$$

where $\theta_{\mathrm{OBS}}$ and $S_{\mathrm{OBs}}$ are the observed potential temperature and salinity, $K_{H}$ and $K_{S}$ are the vertical mixing coefficients for temperature and salinity, $C_{p}$ is the specific heat, $Q_{H}$ and $Q_{S}$ are surface net heat and salinity fluxes, and $E$ and $P_{r}$ are evaporation and precipitation rates, respectively. The relaxation coefficient $C$ is the reciprocal of the restoring time period for a unit volume of water. The two weights, $\alpha_{1}=1$ and $\alpha_{2}=0$, would specify only flux forcing is applied; $\alpha_{1}=0$ and $\alpha_{2}=$ 1 would specify that only restoring-type forcing is applied. The relaxation coefficient $C$ is taken to be $0.7 \mathrm{~m}$ day ${ }^{-1}$, which is equivalent to a relaxation time of 43 days for an upper layer $30 \mathrm{~m}$ thick (Chu et al. 1998a, 1999a-c). The net effect is to prevent any large deviations from climatology. Chu et al. (1998b) pointed out that the pure restoring boundary condition $\left(\alpha_{1}=0\right.$ and $\alpha_{2}=1$ ) is not applicable to coastal regions.

\section{c. Lateral boundary forcing}

Rigid lateral boundaries, that is, the modeled ocean bordered by land, were defined using a free-slip condition for velocity and a zero gradient condition for temperature and salinity. No advective or diffusive heat, salt, or velocity fluxes occur through these boundaries. Open boundaries, where the numerical grid ends but the fluid motion is unrestricted, were treated as radiative boundaries. When the water flows into the model domain, temperature and salinity at the open boundary are likewise prescribed from the climatological data (Levitus 1982). When water flows out of the domain, the radiation condition is applied,

$$
\frac{\partial}{\partial t}(\theta, S)+U_{n} \frac{\partial}{\partial n}(\theta, S)=0
$$



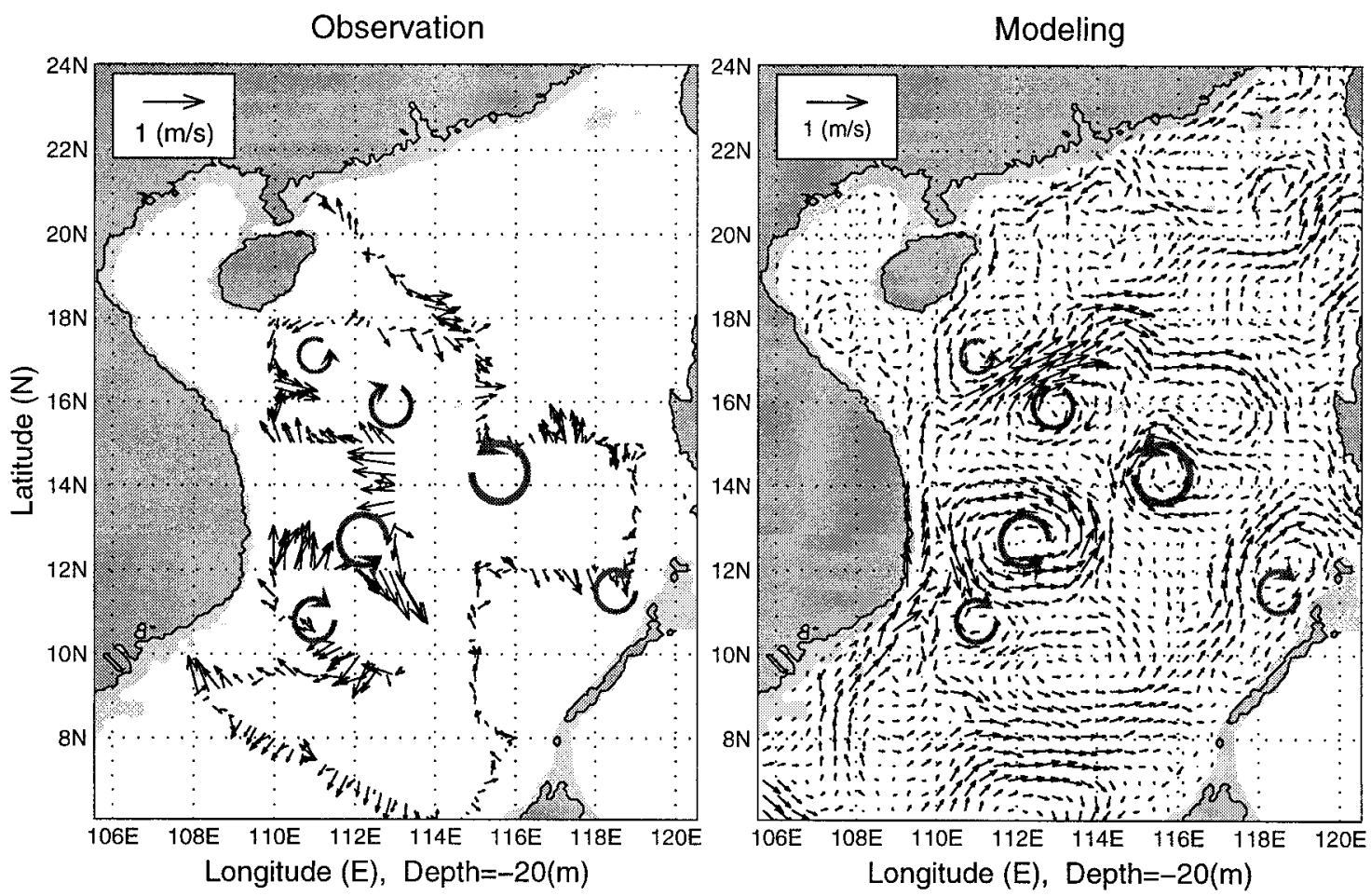

FIG. 6. Horizontal velocity vectors (May-Jun 1998) at 20-m depth (a) obtained from ADCP observations and (b) predicted from $\mathrm{MD}_{2}$.

where the subscript $n$ is the direction normal to the boundary.

The volume transports through major straits of the SCS are uncertain. For example, different authors reported volume transport through the Luzon Strait ranging from 8 to $10 \mathrm{~Sv}$ (e.g., Huang et al. 1994), 6.5 Sv (Chu and Li 2000) to 2-3 Sv (Wyrtki 1961; Metzger and Hurlburt 1996). It is not clear how to choose one among various estimates of the volume transport. Despite being old, Wyrtki's (1961) data provide a balanced estimate of volume transports for the Luzon Strait, Taiwan Strait, and Gasper and Karimata Straits with seasonal variations (Table 2). Since there are no reliable estimates at Balabac Channel, Mindoro Strait, and the Strait of Malacca, we assumed zero transport there. Such a treatment, especially at Mindoro Strait, may distort the solution.

\section{d. Two-step initialization}

First, we integrate POM for 3 yr from zero velocity and January climatological temperature and salinity fields (Levitus 1982) with climatological monthly mean surface wind stress from the Comprehensive Ocean and Atmosphere Data Set (COADS; da Silva et al. 1994) and restoring-type thermohaline surface forcing $\left(\alpha_{1}=\right.$ $0, \alpha_{2}=1$ ), which are relaxed to the surface monthly mean values. Second, we continue to integrate POM for
$2 \mathrm{yr}$ and 3 months with monthly mean surface wind stress and heat and salt fluxes $\left(\alpha_{1}=1, \alpha_{2}=0\right)$ from COADS. The final states of temperature, salinity, and velocity fields are taken as the initial ocean conditions (1 Apr 1998) for model evaluation.

\section{e. CTD data assimilation}

We use the intermittent optimal interpolation (OI) scheme developed at Harvard University (Robinson et al. 1996; Lozano et al. 1996) to assimilate the SCSMEX CTD data daily. The large-scale OI was used to estimate the background mean with a decorrelation scale of 450 $\mathrm{km}$. The mesoscale OI was used to map the observational anomaly from the background mean field into a regular grid with a spatial decorrelation scale of $75 \mathrm{~km}$ and a temporal decorrelation scale of 10 days (Chu et al. 1998c). The spatial and temporal decorrelation scales associated with the mean field were estimated from the covariance matrix obtained from the navy's Master Oceanographic Observational Data Set for the SCS (see Chu et al. 1997c). The large-scale mean was computed using the temperature and salinity profiles. The decorrelation length scale for the fluctuations from the mean was estimated from the synoptic data (Chu et al. 1998c). The decorrelation timescale was selected to ensure synopticity. The SST horizontal scales seem somewhat larger than those of temperatures in the seasonal thermo- 

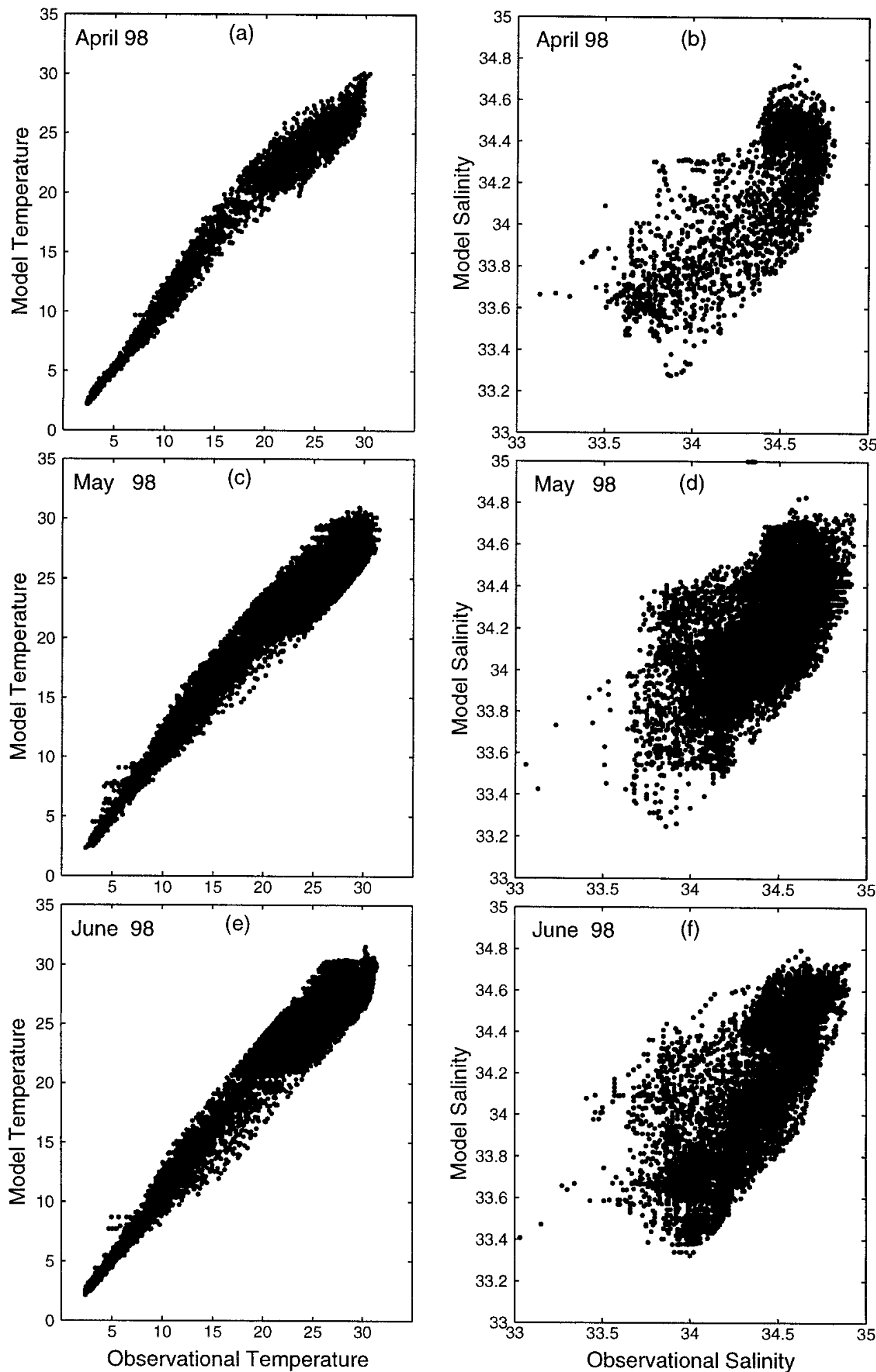

FIG. 7. Scatter diagram of the $\mathrm{MD}_{1}$ data the SCSMEX data. 

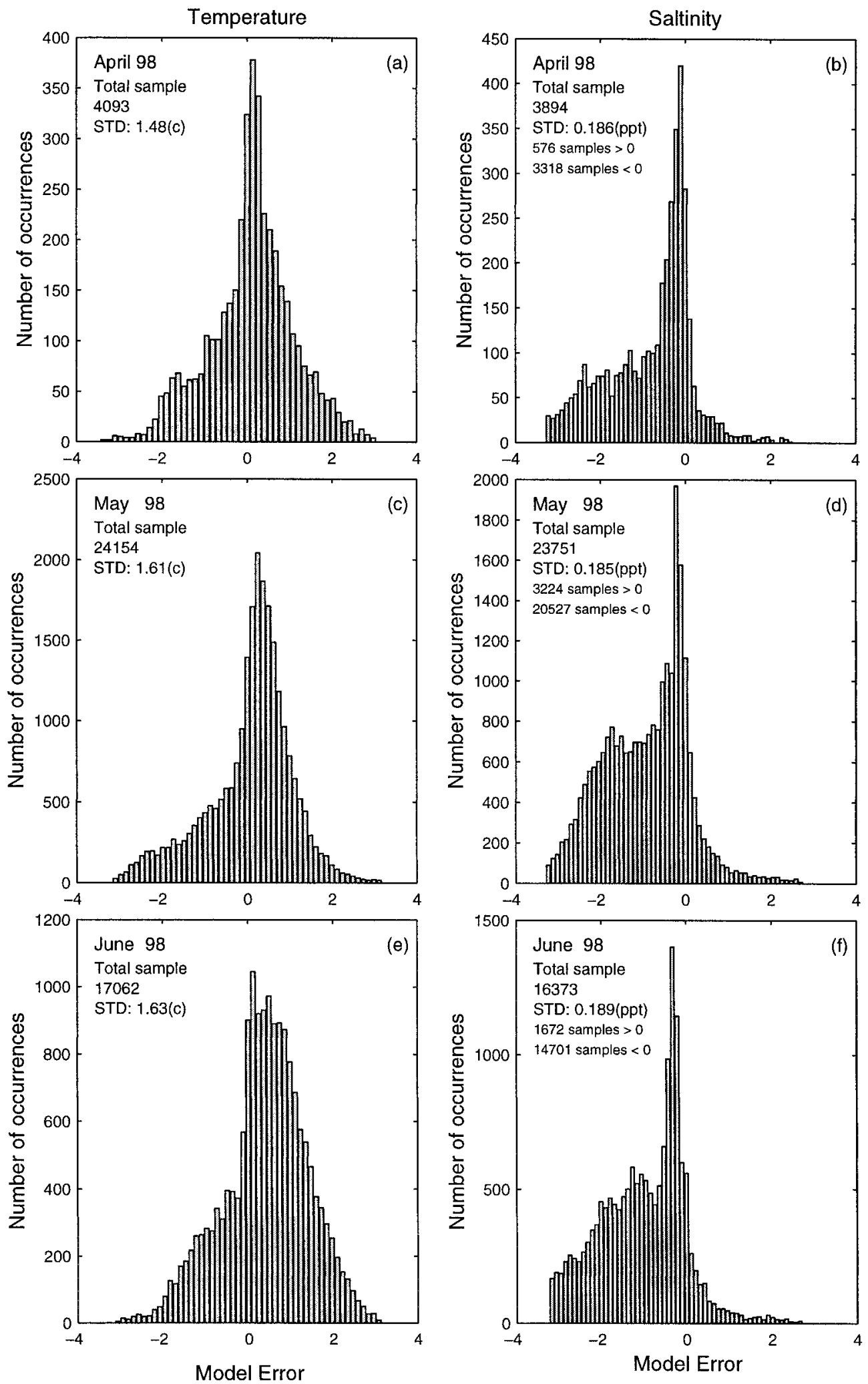

FIG. 8. Histogram of model $\left(\mathrm{MD}_{1}\right)$ errors of temperature $\left({ }^{\circ} \mathrm{C}\right)$ and salinity (ppt). 

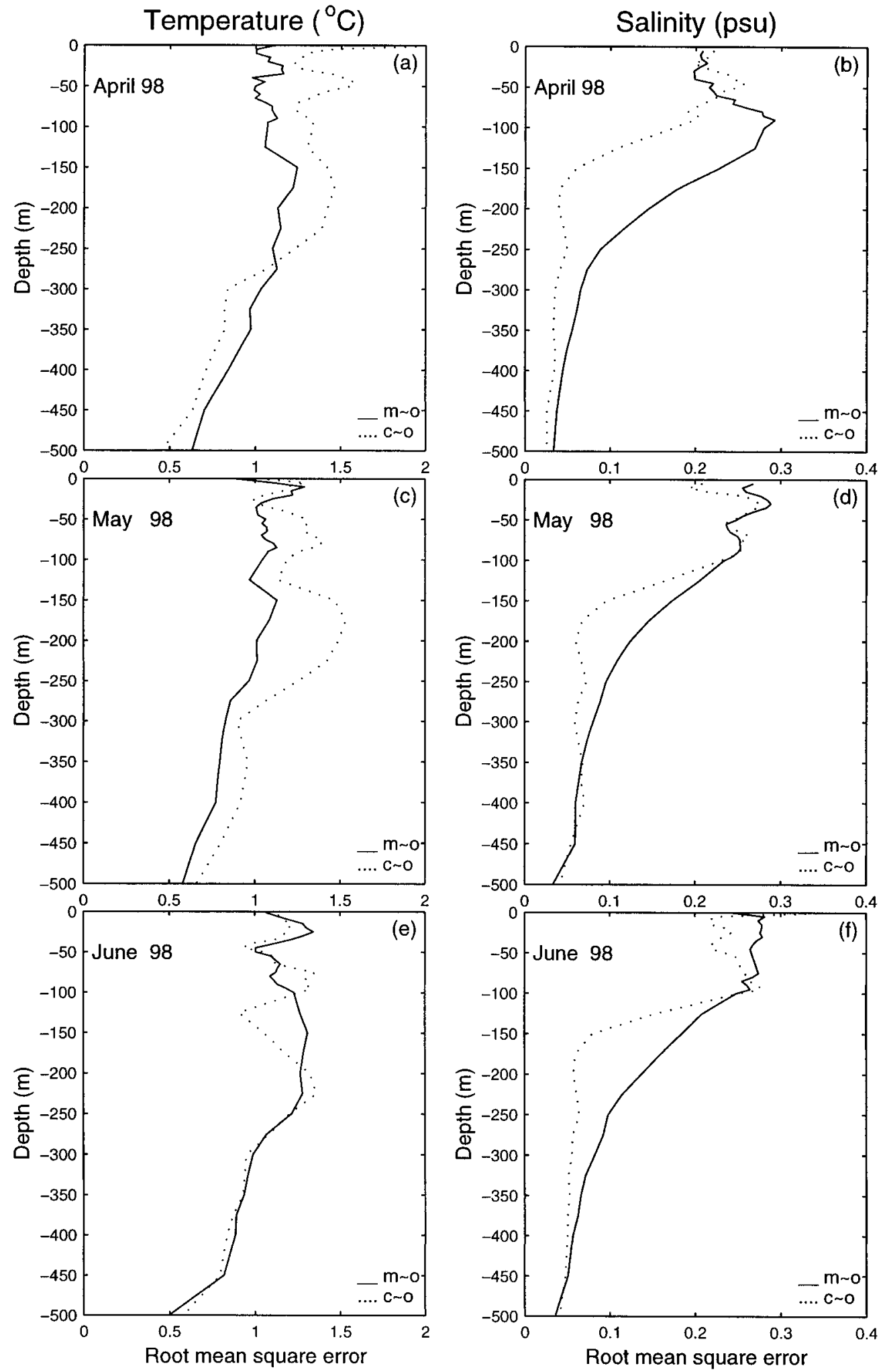

FIG. 9. The rmse between the $\mathrm{MD}_{1}$ and the SCSMEX CTD data (temperature, ${ }^{\circ} \mathrm{C}$; salinity, ppt). 

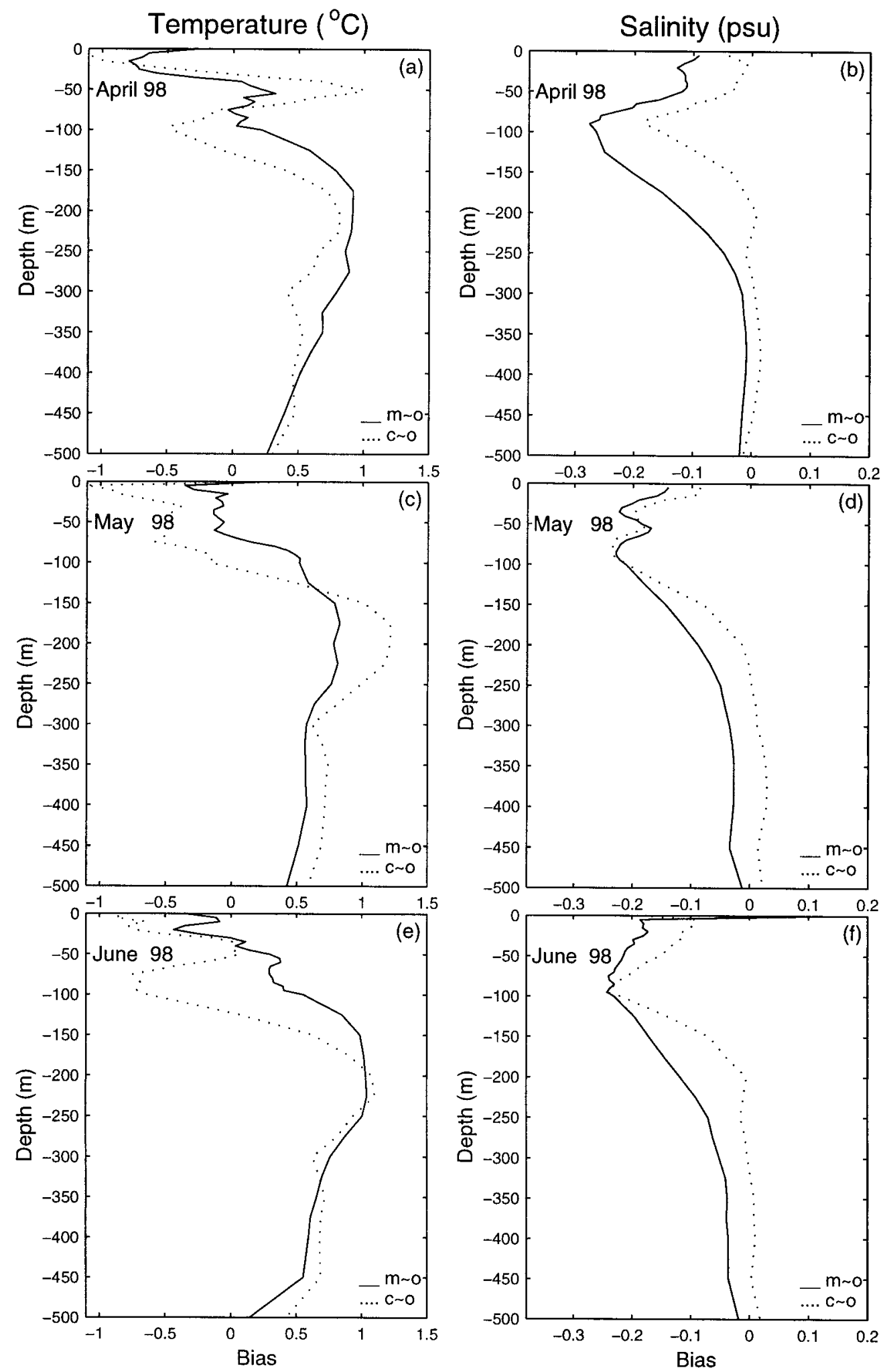

FIG. 10. The bias between the $\mathrm{MD}_{1}$ and the SCSMEX CTD data (temperature, ${ }^{\circ} \mathrm{C}$; salinity, ppt). 

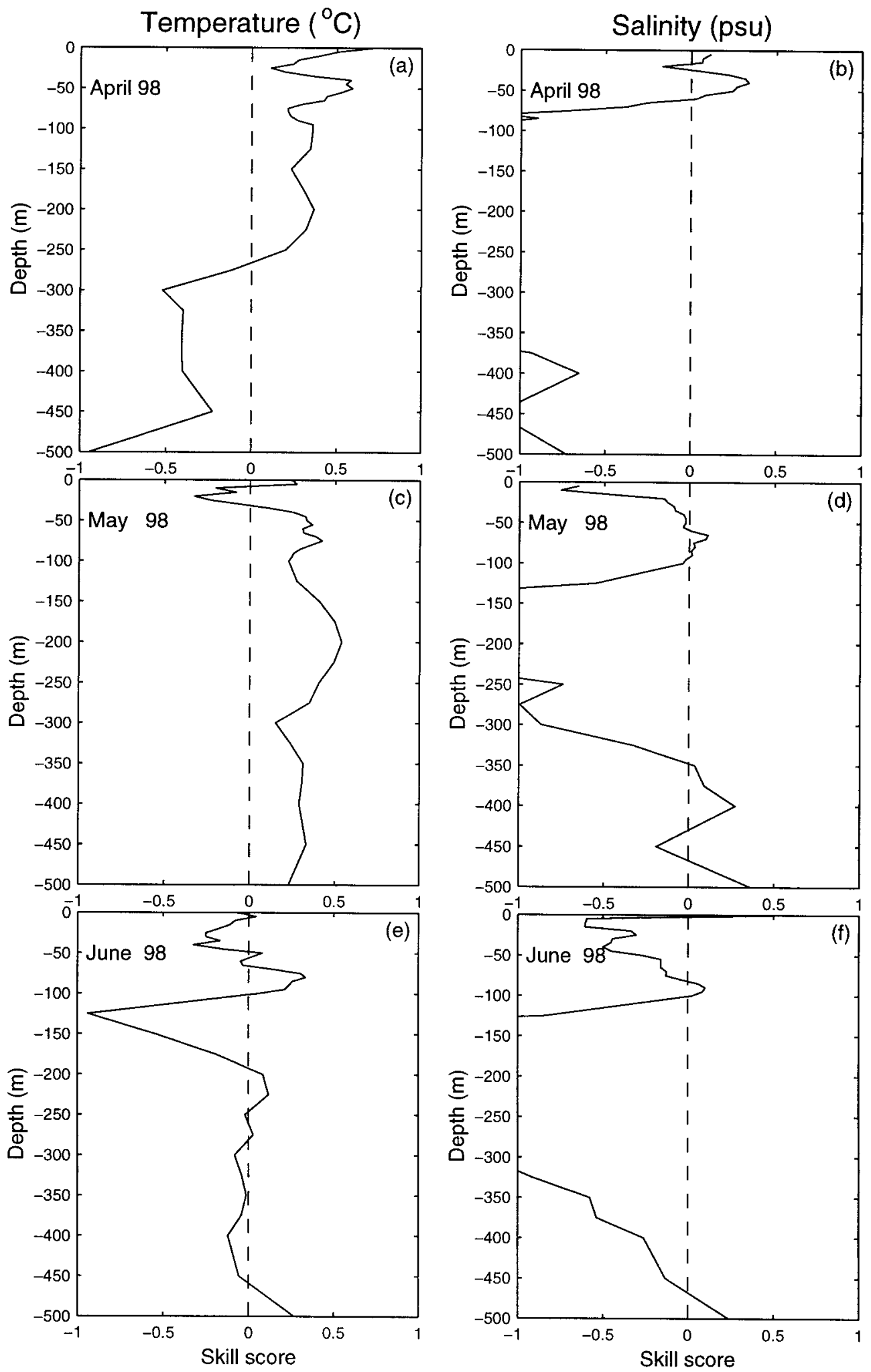

FIG. 11. Skill score for POM without data assimilation $\left(\mathrm{MD}_{1}\right.$ data). 

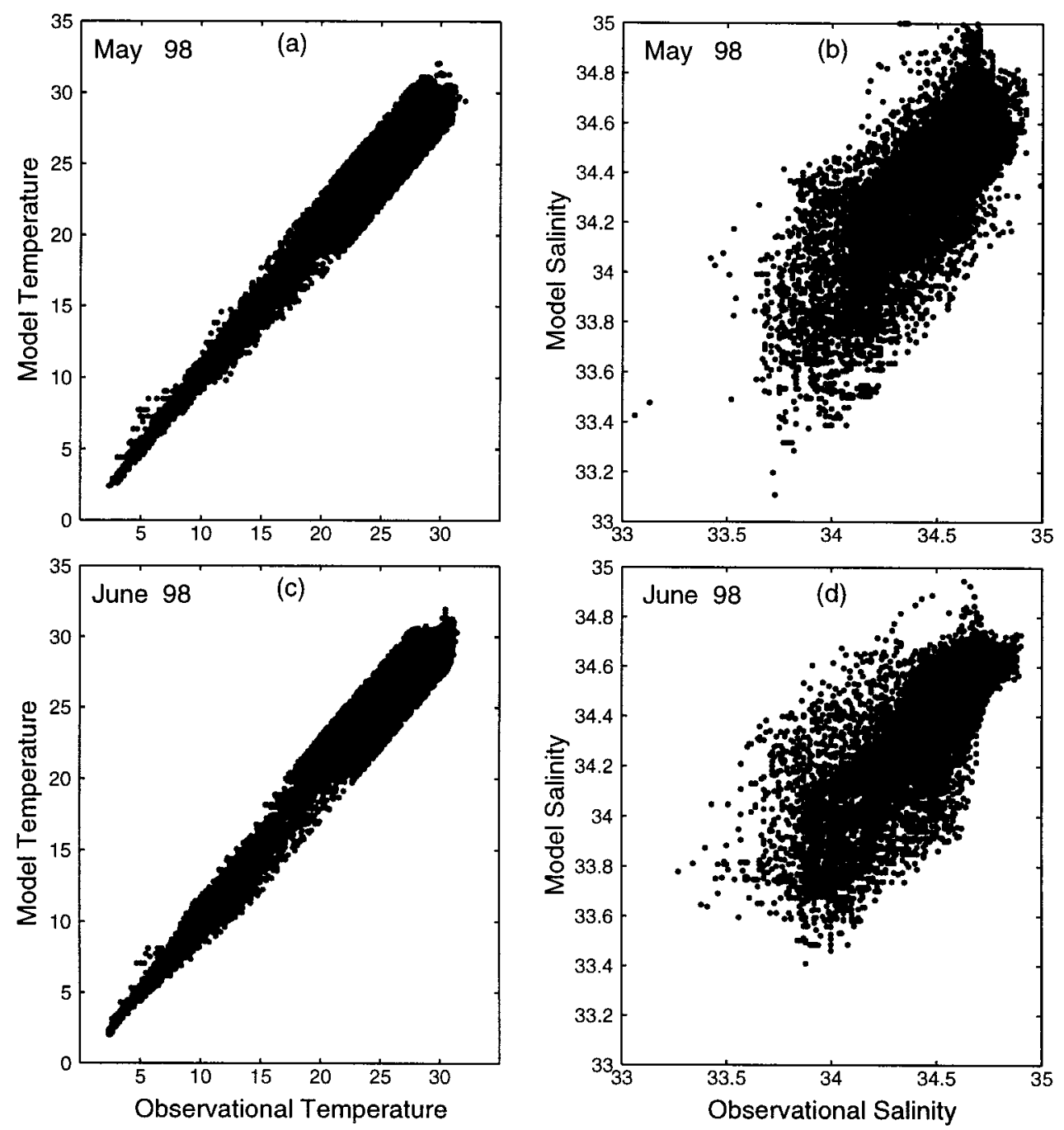

FIG. 12. Scatter diagram of the $\mathrm{MD}_{2}$ data the SCSMEX data.

cline. In this study, we choose horizontal scales to be uniform in the vertical for convenience.

\section{f. Model integration}

We integrate the POM-SCS model from the state of 1 April 1998 with daily surface wind stress and heat and salt fluxes $\left(\alpha_{1}=1, \alpha_{2}=0\right)$ for 3 months from National Centers for Environmental Prediction data in two cases: 1) without any data assimilation (defined as $\mathrm{MD}_{1}$ ) and 2) with daily SCSMEX-CTD data assimilation (defined as $\mathrm{MD}_{2}$ ).

To verify the model's hindcast capability, we should define hindcast periods during which the observational data are not assimilated. The hindcast period for $\mathrm{MD}_{1}$ is 3 months (1 Apr-30 Jun 1998); $\mathrm{MD}_{1}$ was evaluated simply by direct comparison between the modeled and SCSMEX data.

The hindcast periods for $\mathrm{MD}_{2}$ are May and June 1998.
For the May (Jun) $\mathrm{MD}_{2}$ hindcast, we use the states of 30 April (31 May) from the assimilation run $\left(\mathrm{MD}_{2}\right)$ as the new initial conditions to integrate POM for a month with no data assimilation. Then $\mathrm{MD}_{2}$ was evaluated by comparison between the reinitialization model and the SCSMEX CTD data for May and June 1998. If $\mathrm{MD}_{2}$ has better capability than $\mathrm{MD}_{1}$, we may confirm the value added by the CTD data assimilation.

The circulation and the thermohaline structures from both runs $\left(\mathrm{MD}_{1}\right.$ and $\left.\mathrm{MD}_{2}\right)$ show similar patterns. The predicted SCS surface circulation is generally anticyclonic during the SCSMEX period (Apr-Jun 1998), with a strong western boundary current, splitting and partially leaving the coast; the bifurcation point is at $14^{\circ} \mathrm{N}$ in May, and shifts southward in June. Recently, we have reported POM-SCS model results (e.g., Fig. 3) in a series of papers (Chu et al. 1999a-c; Chu et al. 2000a,b), and thus in this paper, we mainly show the results of the model verification. 

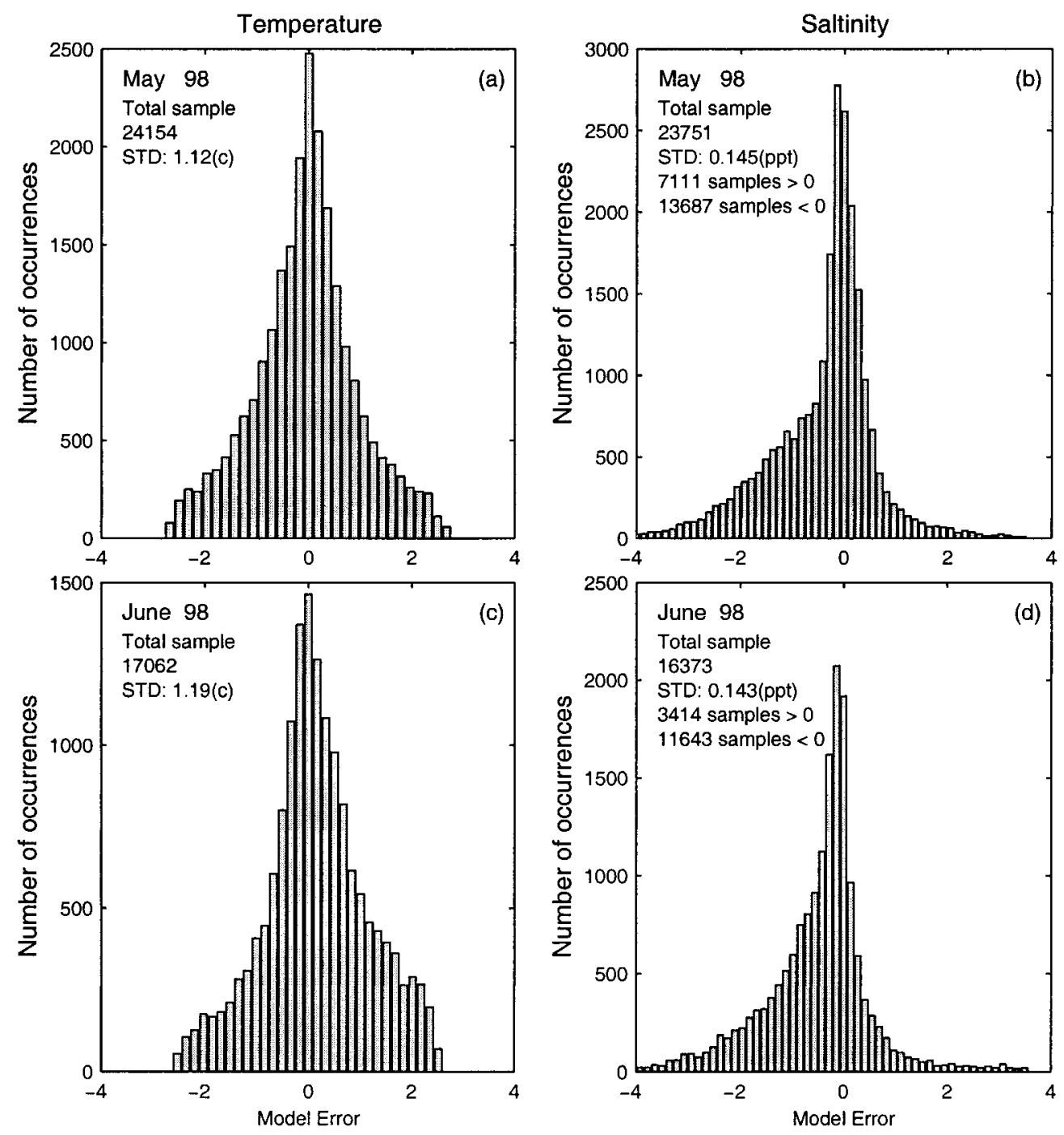

FIG. 13. Histogram of model $\left(\mathrm{MD}_{2}\right)$ errors of temperature $\left({ }^{\circ} \mathrm{C}\right)$ and salinity (ppt).

The predicted $20-\mathrm{m}$ depth (Fig. $6 \mathrm{~b}$ ) velocity vector fields (averaged over May-Jun 1998) from $\mathrm{MD}_{2}$ show the multieddy structure with a central SCS anticyclonic gyre surrounded by north cyclonic-south anticyclonic dipoles $\left(9^{\circ}-14^{\circ} \mathrm{N}, 110^{\circ}-113^{\circ} \mathrm{E}\right)$ near the Vietnamese Bight, an anticyclonic eddy $\left(8^{\circ}-13^{\circ} \mathrm{N}, 115^{\circ}-120^{\circ} \mathrm{E}\right)$ west of Palawan Island, and a cyclonic eddy $\left(17^{\circ}-21^{\circ} \mathrm{N}\right.$, $110^{\circ}-113^{\circ} \mathrm{E}$ ) east of Hainan Island. The predicted multieddy structure is consistent with the SCSMEX ADCP data.

\section{Methodology of verification}

The observational data are located at depth $z$. We interpolate the model data into the observational points $\left(x_{i}, y_{j}, z, t\right)$ and form two sets of modeled data: $\mathrm{MD}_{1}$ and $\mathrm{MD}_{2}$.

\section{a. Error distribution}

The difference of the modeled and observed variable $\psi$,

$\Delta \psi\left(x_{i}, y_{j}, z, t\right)=\psi_{m}\left(x_{i}, y_{j}, z, t\right)$

$$
-\psi_{o}\left(x_{i}, y_{j}, z, t\right)
$$

represents the model error. Here $\psi_{m}$ and $\psi_{o}$ are the variables from model and observation, respectively. We may take the probability histogram of $\Delta \psi$ as the error distribution.

\section{b. Basic statistical parameters}

Three parameters: Bias, mean-square error (mse), and root-mean-square error (rmse), 

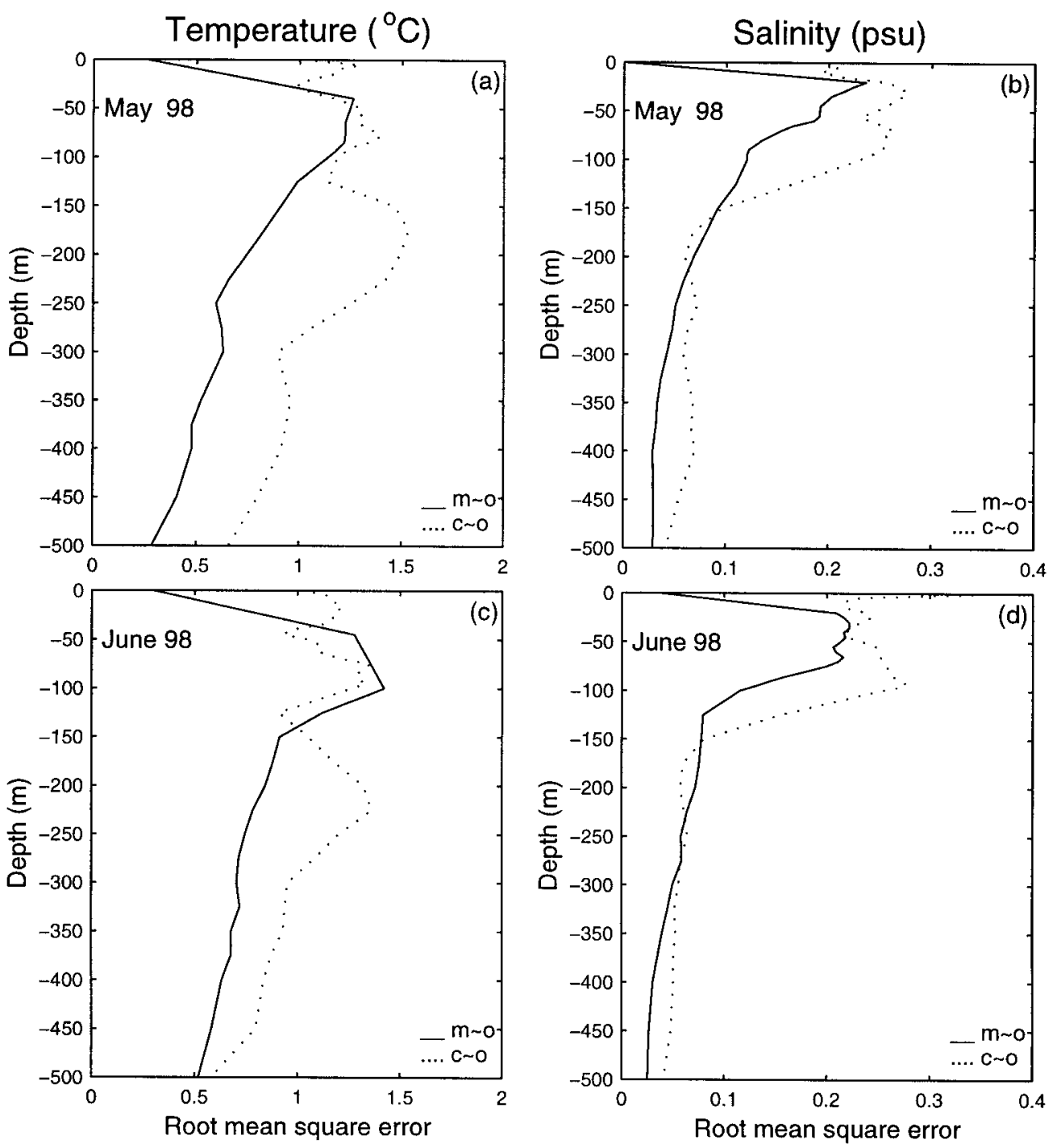

FIG. 14. The rmse between the $\mathrm{MD}_{2}$ and the SCSMEX CTD data (temperature ${ }^{\circ} \mathrm{C}$; salinity, ppt).

$$
\begin{aligned}
\operatorname{bias}(z, t) & =\frac{1}{N} \sum_{i} \sum_{j} \Delta \psi\left(x_{i}, y_{j}, z, t\right), \\
\operatorname{mse}(z, t) & =\sum_{i} \sum_{j} \frac{1}{N}\left[\Delta \psi\left(x_{i}, y_{j}, z, t\right)\right]^{2}, \\
\operatorname{rmse}(z, t) & =\sqrt{\operatorname{mse}(z, t)},
\end{aligned}
$$

are commonly used for evaluation of the model performance. Here $N$ is the total number of horizontal points, and $\left[\bar{\psi}_{m}(z, t), \bar{\psi}_{o}(z, t)\right]$ and $\left[\sigma_{m}(z, t), \sigma_{o}(z, t)\right]$ are horizontal means and standard deviations of the modeled and observed data.

\section{c. Model accuracy and skill}

Model accuracy is usually defined as the average degree of correspondence between modeled and ob- servational data. Thus, the mse or rmse represents a prototype measure of accuracy. Model skill, on the other hand, is defined as the model accuracy relative to the accuracy of hindcasts produced by some reference procedure such as climatology or persistence. To measure the model skill, we may compute the reduction of mse over the climatological hindcasts (Murphy 1988),

$$
\mathrm{SS}=1-\frac{\operatorname{mse}(m, o)}{\operatorname{mse}(c, o)},
$$

where mse $(m, o)$ and $\operatorname{mse}(c, o)$ are the mse of the model and climatological hindcasts, respectively. The parameter SS is called the skill score, which is positive (negative) when the accuracy of the hindcasts is greater (less) than the accuracy of the reference hindcasts (climatology). Moreover, $\mathrm{SS}=1$ when $\operatorname{mse}(m$, 
$o)=0$ (perfect hindcasts) and SS $=0$ when $\operatorname{mse}(m$, $o)=\operatorname{mse}(c, o)$. To compute $\operatorname{mse}(c, o)$, we interpolate the climatological monthly temperature and salinity data (Levitus 1982) into the observational points $\left(x_{i}\right.$, $\left.y_{j}, z, t\right)$.

\section{Evaluation of POM without data assimilation}

We compare the $\mathrm{MD}_{1}$ data against the SCSMEX CTD data to verify POM-SCS model without data assimilation.

\section{a. Statistical evaluation}

The easiest way to verify POM-SCS performance is to plot the MD data against SCSMEX CTD data (Fig. 7). The scatter diagrams for temperature show the points clustering around the line of $T_{m}=T_{o}$. The scatter diagrams for salinity show much more spreading out of the points around the line $S_{m}=S_{o}$. This result indicates better performance in temperature hindcast than in salinity hindcast.

The model errors for temperature hindcast have Gaussian-type distribution with mean values approximately zero and values of standard deviation (STD) increasing with integration time from $1.48^{\circ} \mathrm{C}$ in April and $1.63^{\circ} \mathrm{C}$ in June (Fig. 8), but the model errors for salinity hindcast reveal non-Gaussian distribution (Fig. 8) with quite steady STD values (0.186-0.189 ppt) and with six to eight times more frequencies of occurrence on the negative side than on the positive side: $3318(-)$ versus $576(+)$ in April, $20527(-)$ versus $3224(+)$ in May, and 74707 (-) versus 1672 $(+)$ in June. These results indicate that the model underpredicts the salinity.

\section{b. Error estimation}

The rmse of temperature (Fig. 9) between the $\mathrm{MD}_{1}$ data and the SCSMEX data in April is around $1{ }^{\circ} \mathrm{C}$ from the surface to $350 \mathrm{~m}$ and decreases with depth to near $0.5^{\circ} \mathrm{C}$ at $500-\mathrm{m}$ depth. The value of $\operatorname{rmse}(m$, $o)$ increases with time. For the June hindcast, $\operatorname{rmse}(m$, $o$ ) is around $1.3^{\circ} \mathrm{C}$ in the upper layer from the surface to $250 \mathrm{~m}$, and the value of $\operatorname{rmse}(m, o)$ is greater than the value of $\operatorname{rmse}(c, o)$ at most of the depths. This result indicates the POM-SCS model loses its predictability for temperature in 2 months from the initial state (1 Apr 1998) without data assimilation.

The rmse of salinity (Fig. 9) between the $\mathrm{MD}_{1}$ data and the SCSMEX data is smaller than that between the climatological data and the SCSMEX data only in the shallow upper layer (surface to $60-\mathrm{m}$ depth) in April, and greater than that between the climatological data and the SCSMEX data elsewhere in April and all the depths in May and June.

The mean SCSMEX data in April-June 1998 are around $0.5^{\circ}$ warmer than the mean climatological data above the 50-m depth and colder than the mean climatological data below the 50-m depth, and are fresher than the climatological data in all depths, with the maximum bias (0.2-0.25 ppt) at 75-m depth (Fig. 10).

The POM-SCS modeled mean temperature is about $0.5^{\circ} \mathrm{C}\left(0.5^{\circ}-1.0^{\circ} \mathrm{C}\right)$ cooler (warmer) than the SCSMEX data above (below) 50-m depth, and the POM-SCS modeled mean salinity is less that the SCSMEX data with the maximum fresh bias of 0.25 ppt in depths between 50 and $100 \mathrm{~m}$ (Fig. 10).

The skill score of the temperature hindcast (Fig. 11) is positive in April and May, and becomes negative in June, which indicates that the model loses the capability to predict the temperature in 2 months. The skill score of the salinity hindcast (Fig. 11) is negative almost everywhere, which indicates the model has little capability to predict salinity.

\section{Evaluation of POM with the CTD data assimilation}

We compare the $\mathrm{MD}_{2}$ data against the SCSMEX CTD data to verify the valueadded of reinitialization using data assimilation.

\section{a. Statistical evaluation}

We plot the $\mathrm{MD}_{2}$ hindcast data against SCSMEX CTD data (Fig. 12). The points in both temperature and salinity scatter diagrams are more clustered around the lines $T_{m}=T_{o}$ and $S_{m}=S_{o}$ in the assimilated model (Fig. 12) than in the nonassimilated model (Fig. 7). This result indicates the improvement of model reinitialization using the SCSMEX CTD data in an ocean hindcast. For both a temperature and salinity hindcast, the model errors have Gaussian-type distributions (Fig. 13) with much smaller STD values (e.g., $1.19^{\circ} \mathrm{C}, 0.143 \mathrm{ppt}$ in Jun) compared to $\mathrm{MD}_{1}$ (Fig. 8). However, the salinity hindcast errors are two to three times greater on the negative side than on the positive side: $13687(-)$ versus $7111(+)$ in May, and $11643(-)$ versus $3414(+)$ in June. These results indicate that the model $\left(\mathrm{MD}_{2}\right)$ still underpredicts the salinity.

\section{b. Error estimation}

The rmse for temperature (Fig. 14) is $0.2^{\circ} \mathrm{C}$ at the surface, increases with depth to a maximum value of $1.2^{\circ} \mathrm{C}$ (May 1998) or of 1.4 (Jun 1998) at $50-100-\mathrm{m}$ depth, and then decreases with depth to a minimum value of $0.3^{\circ} \mathrm{C}$ (May 1998) or $0.5^{\circ} \mathrm{C}$ at $500 \mathrm{~m}$. The mean rmse is around $0.6^{\circ} \mathrm{C}$. The rmse for salinity (Fig. 14) is near zero at the surface, increases with depth to a maximum value of $0.22 \mathrm{ppt}$ (May 1998) or of $0.21 \mathrm{ppt}$ (Jun 1998) at 25-75-m depth, and then decreases with depth to a minimum value of $0.03 \mathrm{ppt}$ at $500 \mathrm{~m}$. The mean rmse is around $0.06 \mathrm{ppt}$. Both 

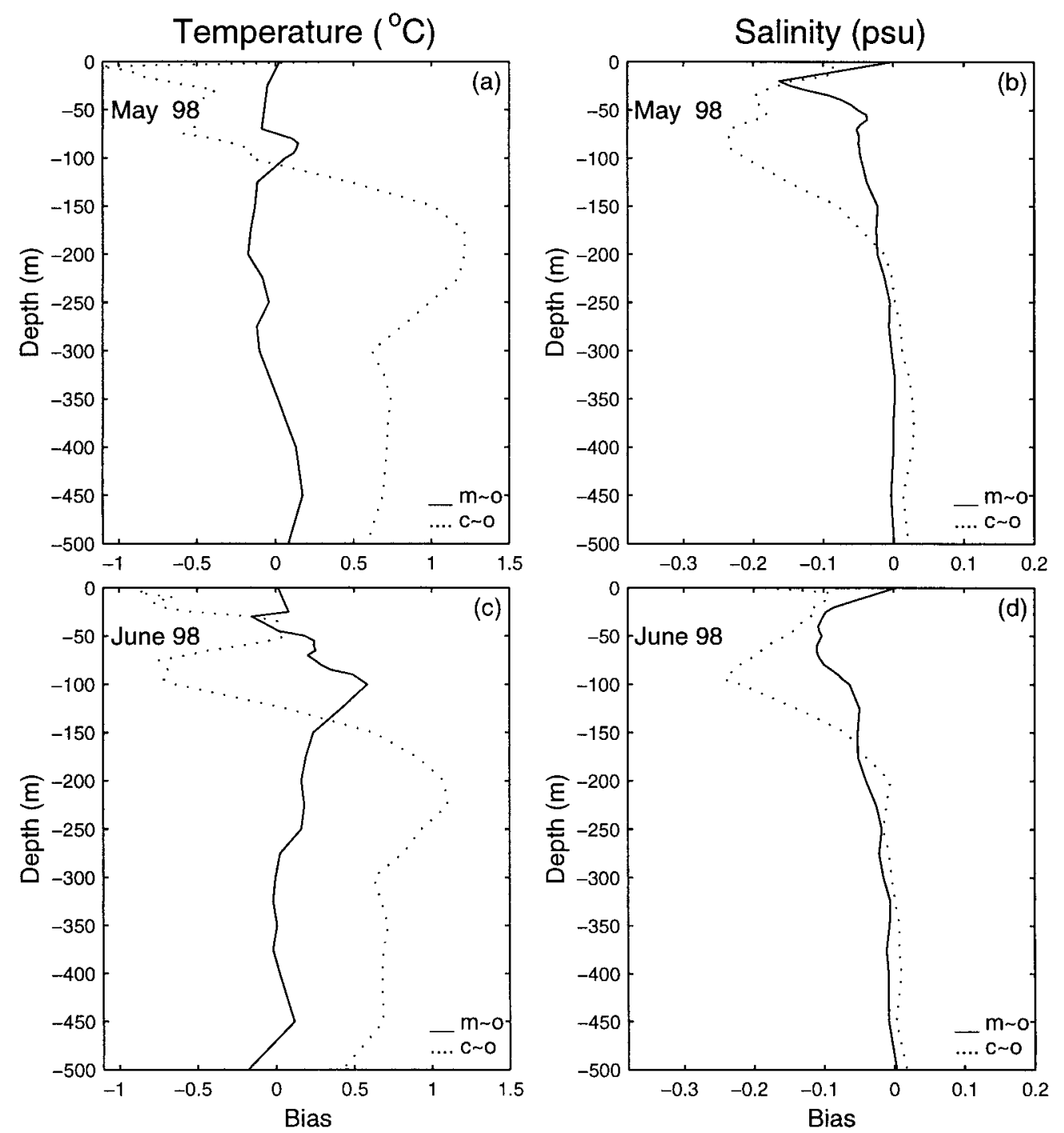

FIG. 15. The bias between the $\mathrm{MD}_{2}$ and the SCSMEX CTD data (temperature, ${ }^{\circ} \mathrm{C}$; salinity, ppt).

temperature and salinity rmse's between the $\mathrm{MD}_{2}$ data and the SCSMEX data (Fig. 14) are smaller than that between the $\mathrm{MD}_{1}$ data and the SCSMEX data (Fig. $9)$, especially for salinity. The $\operatorname{rmse}(m, o)$ for salinity becomes smaller than $\operatorname{rmse}(c, o)$ for almost all the depths in May and June. These results indicate that POM-SCS gains the capability of salinity hindcast if we reinitialize the model monthly with the SCSMEX CTD data. The values of $\operatorname{rmse}(m, o)$ for temperature are also reduced, compared to the $\mathrm{MD}_{1}$ case.

The POM-SCS (with data assimilation) modeled mean temperature is about $0.2^{\circ} \mathrm{C}$ warmer in May (and about $0.5^{\circ} \mathrm{C}$ warmer in Jun) than the SCSMEX data at 100-m depth, and the POM-SCS (with data assimilation) modeled mean salinity is less than the SCSMEX data with the maximum fresh bias of 0.17 ppt at 20-m depth in May 1998 and 0.1 ppt in depths between 25 and $75 \mathrm{~m}$ (Fig. 15).

The skill scores for both temperature and salinity hindcasts (Fig. 16) are much improved compared to $\mathrm{MD}_{1}$ (Fig. 11), especially the salinity hindcast. The skill score of the $\mathrm{MD}_{2}$ model (Fig. 16) for the salinity hindcast is positive except in the sublayer (125-175 $\mathrm{m})$.

\section{Conclusions}

1) The mean SCSMEX data in April-June 1998 are about $0.5^{\circ}$ warmer than the mean climatological data (Levitus 1982) above 50-m depth and cooler than the mean climatological data below 50-m depth. They are fresher than the climatological 

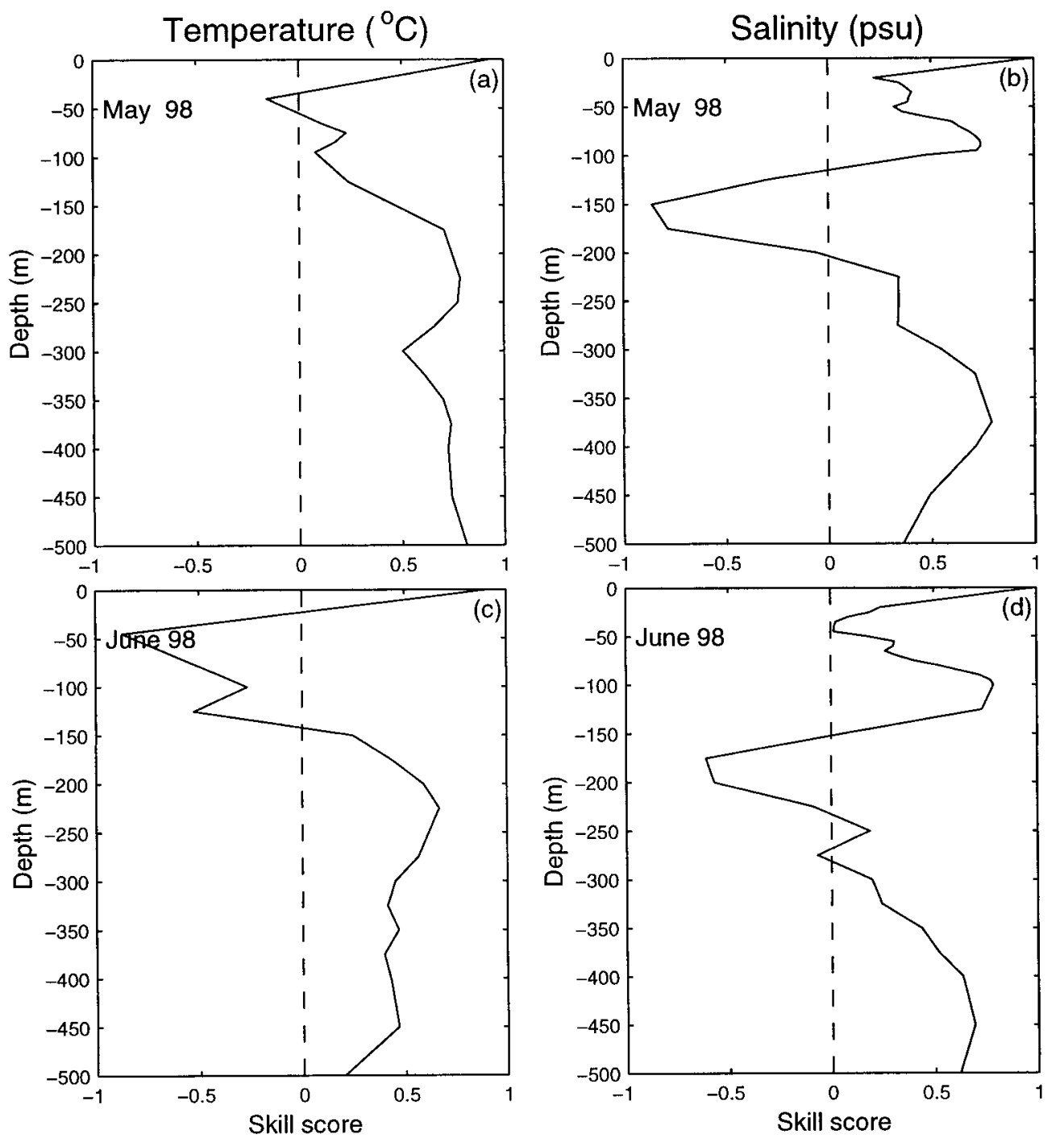

FIG. 16. Skill score for POM with reinitialization $\left(\mathrm{MD}_{2}\right.$ data).

data at all depths, with the maximum bias (0.2$0.25 \mathrm{ppt})$ at $75-\mathrm{m}$ depth.

2) POM-SCS with pure surface flux forcing and without data assimilation has the capability to predict the temperature filed reasonably well, but has little capability to predict the salinity field. The model errors for temperature hindcast have a Gaussian-type distribution, but the model errors for salinity hindcast reveal a non-Gaussian distribution with six to eight time more frequencies of occurrence on the negative side than on the positive side. This result indicates that the model underpredicts the salinity. The skill score of the temperature hindcast is positive in April and May, and becomes negative in June, which indicates that the model will lose the capability to predict the temperature in 2 months without data assimilation. The skill score of the salinity hindcast is negative almost everywhere, which indicates a lack of capability in salinity hindcast.

3) Data assimilation enhances the model capability for an ocean hindcast, even if only CTD data are assimilated. When we reinitialize the model using the assimilated data at the end of a month (30 Apr, 30 May 1998), the model errors for both the temperature and salinity hindcasts have Gaussian-type distributions. Both temperature and salinity rmse's are smaller with the CTD data assimilation than that without the data assimilation, especially for salinity. With the data assimilation, the mean rmse for temperature is around $0.6^{\circ} \mathrm{C}$, and for salinity is around $0.06 \mathrm{ppt}$.

Acknowledgments. The authors wish to thank George Mellor and Tal Ezer of Princeton University 
for most kindly providing a copy of the POM code and also wish to thank Chenwu Fan for programming assistance. This work was funded by the Office of Naval Research, the Naval Oceanographic Office, and the Naval Postgraduate School.

\section{REFERENCES}

Blumberg, A., and G. Mellor, 1987: A description of a three dimensional coastal ocean circulation model. Three-Dimensional Coastal Ocean Models, N. S. Heaps, Amer. Geophys. Union, 1-16.

Chu, P. C., and R. F. Li, 2000: South China Sea isopycnal surface circulations. J. Phys. Oceanogr., 30, 2419-2438.

—_, S. H. Lu, and Y. C. Chen, 1997a: Temporal and spatial variabilities of the South China Sea surface temperature anomaly. J. Geophys. Res., 102, 20 937-20955.

- - H. C. Tseng, C. P. Chang, and J. M. Chen, 1997b: South China Sea warm pool detected in spring from the Navy's Master Oceanographic Observational Data Set (MOODS). J. Geophys. Res., 102, 15 761-15 771.

_- S. K. Wells, S. D. Haeger, C. Szczechowski, and M. Carron, 1997c: Temporal and spatial scales of the Yellow Sea thermal variability. J. Geophys. Res., 102, 5655-5667.

-, Y. C. Chen, and S. H. Lu, 1998a: Wind-driven South China Sea deep basin warm-core/cool-core eddies. J. Oceanogr., 54, 347-360.

— - - and ——, 1998b: On Haney-type surface thermal boundary conditions for ocean circulation models. J. Phys. Oceanogr., 28, 890-901.

_- C. Fan, C. J. Lozano, and J. L. Kerling, 1998c: An airborne expandable bathythermograph survey of the South China Sea, May 1995. J. Geophys. Res., 103, 21 637-21 652.

——, N. L. Edmons, and C. W. Fan, 1999a: Dynamical mechanisms for the South China Sea seasonal circulation and thermohaline variabilities. J. Phys. Oceanogr., 29, 2971-2989.

—_, S. H. Lu, and Y. C. Chen 1999b: A coastal atmosphereocean coupled system (CAOCS) evaluated by an airborne expandable bathythermograph survey in the South China Sea, May 1995. J. Oceanogr., 55, 543-558.

_ _ _ - and W. T. Liu, 1999c: Uncertainty of the South China Sea prediction using NSCAT and NCEP winds during Tropical Storm Ernie 1996. J. Geophys. Res., 104, 11 273-11 289.
, C. W. Fan, and W. T. Liu, 2000a: Determination of subsurface thermal structure from sea surface temperature. J. Atmos. Oceanic. Technol., 17, 971-979.

- - J. M. Veneziano, and C. W. Fan, 2000b: Response of the South China Sea to Tropical Cyclone Ernie 1996. J. Geophys. Res., 105, 13 991-14 009.

da Silva, A. M., C. C. Young, and S. Levitus, 1994: Atlas of surface marine data 1994. Tech. Rep. 94, University of Wisconsin-Milwakee, $83 \mathrm{pp}$.

Hu, J., and M. Liu, 1992: The current structure during summer in southern Taiwan Strait (in Chinese). Tropic Oceanol., 11, 4247.

Huang, Q., W. Wang, Y.-S. Li, and C.-W. Li, 1994: Current characteristics of the South China Sea. Oceanology of China Seas, Z. Di, L. Yuan-Bo, and Z. Cheng-Kui, Eds., Kluwer, 39-46.

Levitus, S., 1982: Climatological Atlas of the World Ocean. NOAA Professional Paper, 13, U.S. Government Printing Office, Washington DC, $173 \mathrm{pp}$.

Lozano, C. J., A. R. Robinson, H. G. Arango, A. Gangopadhyay, Q. Sloan, P. J. Haley, L. Anderson, and W. Leslie, 1996: An interdisciplinary ocean prediction system: assimilation strategies and structured data models. Modern Approaches to Data Assimilation in Ocean Modeling, P. Malanotte-Rizzoli, Ed., Elsevier, 413-452.

Metzger, E. J., and H. Hurlburt, 1996: Coupled dynamics of the South China Sea, the Sulu Sea, and the Pacific Ocean. J. Geophys. Res., 101, 12 331-12 352.

Murphy, A. H., 1988: Skill score based on the mean square error and their relationships to the correlation coefficient. Mon. Wea. Rev., 116, 2417-2424.

NAVOCEANO, 1998: Ocean floor depth digital bathymetric data base variable resolution. Oceanographic and Atmospheric Master Library Summary, Naval Oceanographic Office, Stennis Space Center, MS, 63-68.

Robinson, A. R., H. G. Arango, A. Warn-Varnas, W. G. Leslie, A. J. Miller, P. J. Haley, and C. J. Lozano, 1996: Real-time regional forecasting. Modern Approaches to Data Assimilation in Ocean Modeling, P. Malanotte-Rizzoli, Ed., Elsevier, $377-410$

SCSMEX Science Working Group, 1995: The South China Sea Monsoon Experiment (SCSMEX) science plan. NASA Goddard Space Flight Center, Greenbelt, MD, 65 pp.

Wyrtki, K., 1961: Scientific results of marine investigations of the South China Sea and the Gulf of Thailand 1959-1961. Naga Rep., Vol 2, University of California, San Diego, 195 pp. 